\section{ACUTE APPENDICITIS IN INFANCY AND EARLY CHILDHOOD}

BY

\author{
G. L. BUNTON, F.R.C.S. \\ Senior Surgical Registrar, University College Hospital, \\ London
}

Bailey and Love (1949) begin their section on appendicitis with these words: "Over 3,000 persons die annually from acute appendicitis in England and Wales alone. Many of them are in youth or the prime of life. Practically alf these lives could be saved if an early diagnosis were made, and, at this stage, the comparatively simple operation of appendicectomy carried out. The importance of the subject cannot be overstated." Recent years have seen an improvement in the saving of lives, though not necessarily in early diagnosis.

In this paper are reviewed 115 consecutive unselected children whose appendices were removed. They were admitted to the wards of the Westminster Children's Hospital during 1950-2. Thirty-two suffered from "recurrent" appendicitis. The remainder had appendices which were unequivocally demonstrated to be the seat of acute inflammation. All were under 12 years old.

It is not proposed to deal in detail with those in the " recurrent" group or with those over 5, but to make special reference to the 28 cases under 5 . It should be noted that in those cases which have been called " recurrent" there was evidence, either macroscopically or microscopically, of past inflammation in the appendix. Cases in which a normal appendix was removed, either through erroneous diagnosis or during the course of some other operative procedure, are not included.
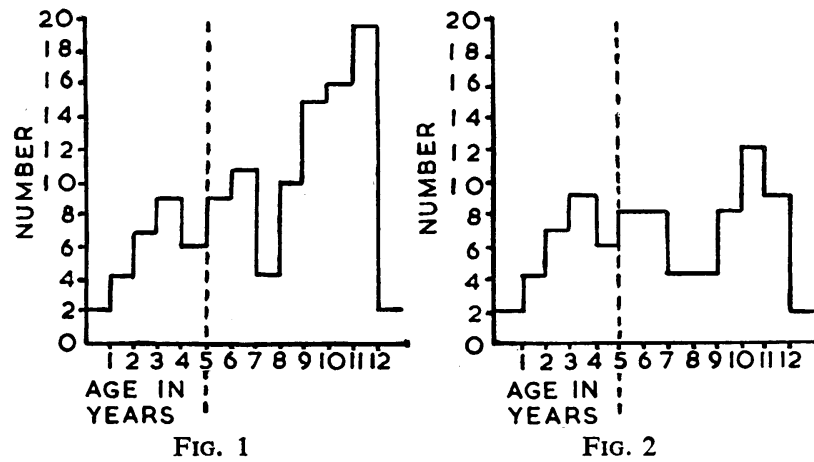

FIG. 1.-Age incidence of whole series. FIG. 2.-Age incidence of non-recurrent cases.

Fig. 1 shows the incidence by age of all cases. Fig. 2 does not include "recurrent" cases. It is seen that quite a high proportion of cases occur under 5, and that " recurrent" appendicitis was not observed at all in this group, which will be subjected to further scrutiny; and the Table sets out those at each age who had complicated appendicitis and in whom there was an

\begin{tabular}{|c|c|c|c|c|c|}
\hline Age & & No. & Complicated & $\begin{array}{l}\text { Recent Upper } \\
\text { Respiratory } \\
\text { Infection }\end{array}$ & $\begin{array}{c}\text { Presenting } \\
\text { with } \\
\text { D. or D. and V. }\end{array}$ \\
\hline \multirow{2}{*}{\multicolumn{2}{|c|}{ 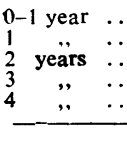 }} & $\begin{array}{l}2 \\
4 \\
7 \\
9 \\
6\end{array}$ & $\begin{array}{l}-2 \\
4 \\
4 \\
2\end{array}$ & $\begin{array}{l}1 \\
2 \\
5 \\
6 \\
4\end{array}$ & $\begin{array}{l}1 \\
2 \\
3 \\
3 \\
2\end{array}$ \\
\hline & & 28 & 12 & 18 & 11 \\
\hline
\end{tabular}

antecedent upper respiratory infection, and the main presenting symptoms. Complicated appendicitis is taken to mean the presence of general or local peritonitis, including abscess formation, on admission.

Several facts now emerge. First, 28 (24\%) cases occurred in children under 5 , and among these the incidence of complicated appendicitis is high, being $43 \%$; whereas in the older children the figure is only $18 \%$. Secondly, a large number of children had diarrhoea, with or without vomiting as a presenting symptom, and in these there was a recent history of an upper respiratory infection. Such a history is often misleading, and judging from these cases it would seem that in the young child acute appendicitis is often missed.

The average duration of symptoms before admission to hospital was four days. Two typical case histories' are given.

\section{Case 1}

A little girl aged 4 was seen one evening in the casualty department. Four days previously she had gone off her food, appeared listless, and complained of abdominal pain. She had recently recovered from a "sore throat," for which a course of penicillin injections was given, and was still having penicillin when her general symptoms appeared. Her temperature, which had fallen to normal limits, rose to $100-101^{\circ} \mathrm{F} .\left(37.8-38.3^{\circ} \mathrm{C}\right.$.) and the penicillin was therefore continued. She seemed to improve somewhat during the next four days but still complained of abdominal pain, and her bowels were opened several times, the motions being very loose. This state of affairs continued until she was brought to hospital.

On admission her temperature was $101^{\circ} \mathrm{F} .\left(38.3^{\circ} \mathrm{C}.\right)$, pulse 120 , and she looked flushed and ill. On examination the abdomen was a little distended and did not move well with respiration. She was tender to palpation in the right iliac fossa and in the midline below the umbilicus, but owing to guarding nothing definite could be felt. On rectal examination, however, a tender mass could be felt high up on the right, and the finger of the glove was covered with mucus.

She was put to bed and kept under observation. By the next day her abdominal pain seemed less, and on careful examination the mass could also be felt through the abdominal wall. It was decided to treat her conservatively, and over the next three weeks the abscess gradually resolved. She was finally sent to convalescence and readmitted four months later, when a fibrotic and still slightly adherent appendix was removed.

\section{Case 2}

A boy aged 3 was admitted with a three-day history of abdominal pain, vomiting, and diarrhoea. At the onset he had started vomiting one evening after his meal. He was put to bed and later complained of abdominal pain, which woke him up. Early next morning he passed two very loose motions. On examination at that time he apparently had few physical signs beyond some tenderness across the lower abdomen. His temperature was $100^{\circ} \mathrm{F}$. $\left(37.8^{\circ} \mathrm{C}\right.$.) It was thought that he might have an enteritis, so a course of chloramphenicol was begun. His symptoms temporarily improved, but his temperature remained between 100 and $101^{\circ}$ F. (37.8 and $38.3^{\circ}$ C.). He had no further diarrhoea, but vomited twice the next day. His pain got no worse. The following day, however, he appeared much worse, the vomiting recurred, and his pulse rose to 130 . The abdomen was by now distended and tense, and showed tenderness all over, especially below the umbilicus. He was immediately sent to hospital.

On admission his temperature was $102.4^{\circ} \mathrm{F}$. $\left(39.1^{\circ} \mathrm{C}.\right)$ and pulse 146. He appeared extremely ill with obvious peritonitis, the abdomen being tense, tender, and silent. At operation a spreading peritonitis was found with little or no attempt at localization, the cause being a gangrenous 
appendix, which was removed. He was given aureomycin intravenously.

His convalescence was stormy and he had a further operation for the relief of small-bowel obstruction due to kinking from an adhesion. However, he was finally fit to go home nine weeks after his operation.

\section{Treatment}

Treatment has in no way differed from that now generally advised by all authorities. Immediate operation is carried out in all early acute cases. Those in whom an abscess has formed are treated conservatively unless spread demands drainage. The appendix is removed four to six months later. Those with peritonitis have had the remains of the appendix removed and the peritoneal cavity drained if the amount and character of the exudate warranted it. Drainage was needed in $9 \%$ of all the cases.

In one respect $I$ find we differ from most other surgeons who have published series of similar cases-that is, in our use of Graham's incision, instead of McBurney's, as advocated by Mr. David Levi. We find it gives an extremely good exposure, is quick to make and close, and is easily extended if more room is required ; also it does not imperil any nerves even if suppuration occurs.

In every recent series published the ultimate credit is given to the antibiotics. Certainly among our own patients there were several who would have undoubtedly died had it not been for these drugs-in particular aureomycin, which was given by intravenous drip. Doses of $100 \mathrm{mg}$. were given six-hourly, dissolved in $10 \mathrm{ml}$. of $1.95 \%$ leucine as supplied by the makers. Five to ten minutes were taken to inject the solution into the drip tubing to avoid undue pain and to minimize the danger of thrombosing the vein. Rapid injections, apart from quickly setting up an irritant thrombosis, cause such intense pain that even a comatose patient is aroused.

Wright et al. (1949) reported six cases of general peritonitis following ruptured appendicitis, all of which recovered with aureomycin. Olshaker et al. (1950), using the same drug, reported six similar successful cases aged between 4 and 8 .

There were no deaths in this series, which, though the numbers are comparatively small, is encouraging.

A "spectacular" drop in mortality in the United States was observed by Slattery et al. (1950) even for the years during the war-from 14,113 in 1939 to 5,285 in 1946 . This they attribute, amongst other factors, to the use of antibiotics and the principle of non-intervention in abscesses. Weiss (1950) reckoned that the total mortality in and around New Orleans had fallen from 15.2 to 2.9 per 100,000 in the last decade.

\section{Pathology}

We found that most cases of acute appendicitis in younger children were catarrhal in origin rather than obstructive. I have no records of some of the earlier cases, but in all those which were examined obstruction by faecalith or stricture was the exception. In the older children faecaliths were common.

The initial site of inflammation is in the lymphoid tissue of the wall-tissue which is far more abundant in youth, and which, like the mesenteric glands, often takes part in infection elsewhere. As already mentioned, over $60 \%$ of these young children give a history of recent tonsillitis, otitis, or a " cold." Babcock (1944) stated that " infections that produce general lymphoid hyperplasia often precede appendicitis." Scott and Ware (1945) denied this, but it seems common experience, in this country at any rate, that upper respiratory tract infections are frequently forerunners of appendicitis.

In addition, it must be realized that the margin of safety in the young is small. A thin-walled appendix containing a mass of lymphoid tissue through which infection spreads easily, and a small ineffective omentum, contribute to early perforation and wide dissemination of infection.

\section{Discussion}

Most authorities seem generally agreed in several points concerning this condition in childhood. First, acute appendicitis is not common in children under 5 . Under 3 it is "rare " or "very uncommon." Reyes and Pascual (1950), reporting a series of 50 cases, found the youngest to be 6 . Secondly, the diagnosis in early childhood is difficult. Thirdly, the mortality is high. The second of these points is undoubtedly true, but for the others there seems less justification at the present time.

Of our 82 patients, 28 (34\%) were under 5, an incidence which cannot be regarded as uncommon. Abel and Allen (1950) reviewed 1,165 cases treated at the Bellevue Hospital, New York, and found that 165 were under 5 . Morton and Kilby (1950) found an incidence of $20 \%$ in 100 cases at Newark, N.J.

Packard and McLauthlin (1951), rewiewing 280 cases at the Denver Children's Hospital during the five-year period 1945-50, found that the average age of patients with peritonitis was 4.8 years. For those with simple appendicitis it was 8.6. Of their patients, $25 \%$ were 4 or under, and of this group $60 \%$ had local or diffuse peritonitis on admission. The only death among these was in a 3-year-old child with a ten-days history.

In searching for some explanation there would appear to be three main causes. First, the difficulties in diagnosis already referred to; secondly, the practitioner is often loath to diagnose acute appendicitis at this age, or thinks of some other condition first because he has been taught that it is uncommon. Such phrases as, "This child seems rather young for an appendix," or, "Could this be appendicitis at this age ?" are often encountered in letters accompanying the patient to hospital. They betray the diagnosis as being late, and even an afterthought. Lastly, I believe the picture of appendicitis at this age to be changing: not because of any alteration in the disease itself but because of the widespread, and in some cases indiscriminate, use of antibiotics.

Difficulties in Diagnosis.-The four earliest signs are pyrexia, abdominal pain, vomiting, and local tenderness. Any of these may predominate, any may be absent, and any may be associated with one other symptom which is uncommon in the older patients-namely, diarrhoea.

Temperature and Pulse.-In a young child very little constitutional upset is enough to produce a considerable rise in temperature and pulse. It is often said that a high temperature associated with abdominal pain is rather against appendicitis and in favour of pyelitis. This is dangerously untrue, especially if a thorough examination of the urine is neglected. Half our patients had temperatures of over $101^{\circ} \mathrm{F}$. $\left(38.3^{\circ} \mathrm{C}\right.$.) and a quarter over $102^{\circ} \mathrm{F}$. (38.9 $9^{\circ} \mathrm{C}$.). The pulse is proportionately raised-a ratio of 12 to each $1^{\circ} \mathrm{F}$. $\left(0.55^{\circ}\right.$ C.) rather than 10 . The rate is not of such importance as a steady rise.

Pain.-This is notoriously difficult to assess in the very young. It is usually colicky or cramp-like and initially comes in waves, causing crying and screaming attacks with the knees drawn up. After a time it becomes continuous and the child lies characteristically curled up. Localization is also poor, and if the patient is of an age to understand the question he usually puts a hand on the umbilicus. Tenderness, on the other hand, is confined to the right iliac fossa unless perforation has already occurred. In the early case a difference in "tension" of the two sides of the abdominal wall is more easily appreciated by very light palpation with the tips of the fingers. Strang (1950) recommends examination of the abdomen from behind with both hands while the child is held in the mother's arms in the natural nursing position. In this way we avoid a crying, frightened child in whom abdominal palpation is impossible. In other cases stealthy examination of the abdomen with the hand under the bedclothes may be better. The disappearance of "abdominal " breathing and its replacement by "thoracic" respiration also occurs surprisingly early on, and must be 
carefully looked for. The most dangerous aspect of pain is its disappearance when perforation occurs. The child, after what may have seemed a trivial abdominal disturbance, appears well for several hours. He may even show a desire for food or fall quietly asleep. The sinister sequence of a steadily increasing pulse and abdominal distension is all too early missed after the parents' and one's own conscience has been reassured. The following morning may be already too late. It is surprising not only how well many such patients appear at this stage but also how rapidly and alarmingly their condition may suddenly deteriorate.

Vomiting and Nausea.-These, with pain, form possibly the commonest manner in which the condition presents. But again a note of warning should be sounded. Reliance on the old axiom " Pain precedes vomiting" can easily mislead; for in many cases the sequence is reversed. Both may be absent.

Diarrhoea.-This may be a cardinal sign, and much more often than is generally supposed it is so. It may occur with or without vomiting. A diagnosis of enteritis or foodpoisoning is fatally easy. How many of us have not had the humiliation of referring an unsuspected acute appendicitis to a fever hospital ? Diarrhoea is often the first presenting sign in infants; the stool is very loose, often containing mucus, but never blood. It is due to the proximity of the appendix to the sigmoid or upper rectum. The child's pelvis is very small compared with the length and size of the appendix, and such contiguity may be demonstrated at operation. The caecum may be similarly irritated. Spurious diarrhoea coming on two or three days after the onset of pain, and consisting of small amounts of faecesstained mucus, is pathognomonic of an appendix abscess. Rectal examination will reveal the mass. Auscultation, while it may show normal or near normal amounts of peristalsis, will not disclose the excited hubbub of the enteritic. Silence means ileus and peritonitis.

The High Appendix.--It is often loosely stated that in children the appendix lies high in the abdomen; sometimes under the liver. This may well be true, and every surgeon at one time or another has experienced confusion in diagnosis and difficulty at operation in removing such an abnormally placed organ. But the condition is a true abnormality. It is a defect in the last stage of the rotation of the gut. It is not common. Only two children in this series showed it, and in only one was it of a degree to cause trouble at operation.

It has been said that the surest sign of appendicitis is tenderness over the appendix, and the proper and usual place for the appendix is just above the brim of the pelvis in the right iliac fossa.

Finally, a point which I believe to be often responsible for the diagnosis being missed. If a child has sought medical aid because of inflammation remote from the peritoneal cavity the almost invariable treatment now afforded is an antibiotic, usually a sulphonamide or penicillin, although chloramphenicol is beginning to gain ground in popularity. The most dangerous complication of these chemicals is the masking of any extension of such inflammation and especially of abscess formation.

Should a metastatic lesion now develop, the classical signs are absent. There is little if any increase in constitutional signs. The appendix can perforate in comparative quietude and large quantities of pus collect without notice. This becomes doubly dangerous in the inarticulate young. As a result the picture of appendicitis is very different from that which used to be taught and expected in practice.

In conclusion it may be said that the only real safeguard is unceasing vigilance-a thorough examination if, and when, any abdominal symptoms develop, which may mean repeated visits even though this is onerous to a busy man.

Professor Aird (1949) has said that the old saying "Never wake a child at night to have an operation" is not dependable, and by the same token should be mentioned $\mathrm{Mr}$.
Levi's maxim that " if abdominal pain in a child, associated with vomiting, lasts continuously for more than six hours and is unrelieved by an enema, he should be seen by a surgeon." Some may dismiss these as " rules of thumb." They may be-but they can be most helpful in times of doubt.

This renewed anxiety concerning the late diagnosis of these little children is not parochial. Packard and McLauthlin (1951) stated that "slower recognition of the diagnosis seems the most important factor in the markedly increased incidence of abscess and peritonitis in the infant and young child," and that " the high incidence of appendicitis with peritonitis in the very young child because of delay in diagnosis presents a challenge."

Riker (1950) out of 136 cases found 56 with rupture on admission: two died. He gives no figure for those in infancy, but states that there was " a high incidence of perforation in early childhood." Hawk et al. (1950) had 139 cases under 10. The youngest was 5 months old, and six out of eight children under 2 had peritonitis. There were no deaths in this series. In Reyes and Pascual's (1950) series $68 \%$ of cases under 10 had local or diffuse peritonitis. In Abel and Allen's (1950) 1,165 cases there was a $10 \%$ mortality in 165 cases under 5 , as opposed to $2.9 \%$ in the remaining thousand. The majority of deaths occurred in the years before the war. Howard Williams (1947), of Melbourne, said of this condition, "Early diagnosis ... will be established only by better clinical training of the student, family physician, and paediatrician." It would seem that the lesson has not yet been learnt.

\section{Summary}

A review of 115 cases of appendicitis is given ; 82 had acute appendicitis. Special reference is made to those aged under 5 . The high incidence $(43 \%)$ of complicated appendicitis in this age group gives cause for concern.

Some difficulties in diagnosis are discussed and a plea is made for earlier diagnosis. It is suggested that the widespread use of antibiotics is changing the picture of appendicitis in the young.

I wish to thank Mr. David Levi and Mr. G. H. Macnab, of the Westminster Children's Hospital, for their helpful advice and criticism.

Biblography

Abel, W. G., and Allen, P. D. (1950). Ann. Surg., 132, 1093.

Aird, I. (1949). Companion in Surgical Studies. Edinburgh.

Babcock, W. W. (1944). Principles and Practice of Surgery. Philadelphia. Bailey, H., and Love, R. J. M. (1949). Practice of Surgery, 8th ed. London. Hawk. J. C., jun., Becker, W. F., and Lehman, E. P. (1950). Ann. Surg., $132,729$.

Ladd, W. E., and Gross, R. E. (1941). Abdominal Surgery in Infancy and Childhood. Philadelphia.

Lawrence, K. B., and Waring, G. W., jun. (1949). New Engl. J. Med., 241, 1 .

Morton, T. V., jun., and Kilby, R. A. (1950). Amer. J. Surg., 80, 576. Olshaker, B., Lopresti, J. M., and Jackson, R. L. (1950). Clin. Proc. Child. Hosp., Wash., 6, 122.

Packard, G. B., and McLauthlin, C. H. (1951). J. Pediat., 39, 708.

Reyes, A. I., and Pascual, A. A. (1950). J. Philipp. med. Ass., 26, 325.

Riker, W. L. (1950). Quart. Bull. Northw. Univ. med. Sch., 24, 49.

Scott, H. W., jun., and Ware, P. F. (1945). Arch. Surg., Chicago, 50, 258. Slattery, L. R., Yannitelli, S. A., and Hinton, J. W. (1950). Ibid., 60, 31. Strang, R. (1950). British Medical Journal, 1, 586.

Weiss, G. N. (1950). New Orleans med. Surg, J, 102,542

Williams, H. (1947). British Medical Journal, 2, 730.

Wright, L. T., et al. (1949). Amer. J. Surg., 78, 15.

Accident Prevention and First Aid in the Home, a 24-page illustrated booklet published by Messrs. E. \& S. Livingstone, Edinburgh (price 1s. 6d.), indicates the commoner precautions that should be taken to prevent accidents in the home, and advises on the measures to be taken and those to be avoided if accidents should occur. Each point is driven home with a suitable illustration. The booklet is intended for mothers and those having the care of small children. It has been compiled by the surgical staff of the Royal Hospital for Sick Children, Edinburgh, and profits from its sale are to be devoted to the treatment of children brought to that hospital as a result of home accidents. 